ORIGINAL ARTICLE

\title{
Increased morbidity from nasopharyngeal carcinoma and chronic pharyngitis or sinusitis among workers at a newspaper printing company
}

\author{
Y-H Liu, C-L Du, C-T Lin, C-C Chan, C-J Chen, J-D Wang
}

Occup Environ Med 2002;59: 18-22

See end of article for authors' affiliations

Correspondence to

Correspondence to:
Dr J-D Wang, Departmen of Internal Medicine,

National Taiwan University

Hospital, Taipei, Taiwan;

jdwang@ha.mc.ntu.edu.tw

Accepted 12 July 2001

\begin{abstract}
Objectives: To determine the association between printing works and nasopharygeal carcinoma as well as other diseases.

Methods: Demographic data were obtained for those who had worked in a particular newspaper company since its establishment in 1950. Through access to the data bank of the hospital records of the Labor Insurance Bureau for 1985-94, all workers were identified who had been admitted to hospital during their employment in the newspaper company. Multiple logistic regressions were performed to estimate the adjusted morbidity odds ratio $(O R)$ for various diseases among the printing workers with cardiovascular diseases as the reference diseases. Biopsy specimens from patients with nasopharyngeal carcinoma were all subjected to in situ hybridisation of Epstein-Barr virus (EBV), and colocalisation of EBV and secretor component protein.

Results: Of the 1564 people who had worked in this company, 579 of them were admitted to hospital at least once. Five out of 144 printing workers admitted to hospital were diagnosed with nasopharyngeal carcinoma compared with none of the other 435 non-printing workers admitted to hospital. The morbidity OR for nasopharyngeal carcinoma in printing workers was $57.0195 \%$ confidence interval $(95 \% \mathrm{Cl}) 2.8$ to 1155.3$)$. The morbidity OR for benign skin tumours was $28.0(95 \% \mathrm{Cl}$ 2.7 to 293.1). Chronic pharyngitis or sinusitis also showed significant relations with printing works with a morbidity OR 29.4 (95\% Cl 1.7 to 514.7). Using all other diseases as the reference diseases for calculation of morbidity ORs still showed a similar trend. In situ hybridisation of EBV encoded small nuclear RNA-1 (EBER-1) showed tumour cells free of the EBV in each biopsy specimen. Colocalisation of EBER-1 and secretor component showed that some tumour cells contained both secretor component and EBV signal in each case.

Conclusion: Printing works are associated with an increased risk of nasopharyngeal carcinoma, benign skin tumours, chronic pharyngitis or sinusitis, chronic liver diseases, and mechanical injuries. Induction of the development of nasopharyngeal carcinoma is probably not related to EBV infection in these patients.
\end{abstract}

use here are various organic solvents, filler materials, and inks used in the printing factory. A survey of materials and substances used in the printing industry in 1978 showed that 2000 products were used, in which 300 chemicals were identified. Among the chemicals, 26 are known or suspected carcinogens according to the classifications made by the International Agency for Research on Cancer. ${ }^{1}$ The printing occupations have been related to an increased mortality and morbidity from various diseases, including an increased mortality from lung cancer, bladder cancer, renal pelvis cancer, primary liver cancer, gall bladder cancer, and liver cirrhosis. ${ }^{1-7}$ There has never been any report on the association between printing occupation and nasopharyngeal carcinoma.

Nasopharyngeal carcinoma is uncommon in most populations, but it occurs with a high frequency in Chinese people, especially in those from the southern provinces of China and Taiwan. ${ }^{8}$ It has been the fifth leading malignant neoplasm for men and the sixth for women in Taiwan since 1983. ${ }^{9}$ Environmental, genetic, and viral factors have been postulated as important determinants of nasopharyngeal carcinoma. ${ }^{10-14}$ However, the pathogenesis of nasopharyngeal carcinoma still awaits further clarification.

At one particular newspaper printing factory there were reported cases of nasopharyngeal carcinoma identified during 1986 to 1993 . We were requested by the labour union and the newspaper company to perform an epidemiological study to determine the associations between printing works and nasopharyngeal carcinoma as well as other diseases.

\section{SUBJECTS AND METHODS \\ Data collection}

Before 1995, the year the Taiwan government implemented a national health insurance system, the Labor Insurance Bureau in Taiwan had provided medical insurance for all laborours who worked in a company with more than five workers. Nearly all the workers in public and private sectors joined the Labor Insurance Bureau. As the Labor Insurance Bureau coverage provides a free choice of doctors and hospitals, full coverage of medical service fees, and partial compensation (about $70 \%-80 \%$ depending on industrial sectors) for wages, our workers would use it whenever they have a major disease that requires admission to hospital. There were around 500000 reimbursement records of admissions to hospital in the Labor Insurance Bureau each year from a population of about 7 million workers. Through access to the database of the Labor Insurance Bureau we retrieved the reimbursement data of

Abbreviations: OR, odds ratio; EBV, Epstein-Barr virus; EBER-1, EBV encoded small nuclear RNA-1; ICD-9, ninth revision of the international classification of diseases; EBVCA, viral capsid antigen associated with the EBV; HBV, hepatitis $B$ virus 
admissions to hospital during 1985-94. The data items included national identification number, age, sex, occupation, hospital, total medical expense, medical record number, insurance number, date and duration of the stay in hospital, as well as the ninth revision of the international classification of diseases ICD-9 code of medical diagnosis.

We also obtained a complete list of workers who have worked in the company since its establishment in 1950. It contained information on demographic characteristics, history of working in a news printing factory, date and duration of employment, etc.

The reimbursement data and list of workers provided by the company were linked together to extract information of the workers who had been admitted to hospital during their employment in the company, regardless of the diagnosis. The relational query by example provided by the Microsoft database software Foxpro was applied for the extraction of information. ${ }^{15}$ For any worker who had been repeatedly admitted to hospital due to the same disease we kept only one record.

Through the procedure we obtained the list of workers affected with nasopharyngeal carcinoma and interviewed them or members of their family about their working and health history. As all workers with nasopharyngeal carcinoma were extracted from the reimbursement data, we are confident that the reimbursement data are comprehensive. With their consent, we reviewed their medical records from different hospitals and summarised the initial symptoms and signs, date of diagnosis, clinical course, treatment received, pathological findings, clinical staging of the disease, and serological titre of antibodies against Epstein-Barr virus.

\section{In situ hybridisation of EBER-1 and double localisation of EBER-1 and secretor component}

Paraffin sections from four out of five patients with nasopharyngeal carcinoma were obtained from four different hospitals, including National Taiwan University Hospital, Kaoshuong Medical College Hospital, Macky Memorial Hospital and Veteran General Hospital (one of the paraffin blocks was missed in Tri-Service General Hospital). The paraffin sections after deparaffinisation were subjected to in situ hybridisation for localisation of EBV encoded small nuclear RNA-1 (EBER-1) with antisense riboprobe as described previously, ${ }^{16}$ Some sections were counter stained with methyl green; others were not. In each case, stain with haematoxylin and eosin was also performed. At the same time we also performed double localisation of EBER-1 and secretor component

Table 1 Characteristics of workers in a newspaper company who had ever been admitted to hospital, and workers admitted to hospital for cardiovascular diseases (the reference group)

\begin{tabular}{|c|c|c|}
\hline Workers & Printing & Non-printing \\
\hline \multicolumn{3}{|l|}{ All workers: } \\
\hline $\operatorname{Men}(n)$ & 331 & 995 \\
\hline Women (n) & 5 & 233 \\
\hline Age $(y$, mean $(S D))$ & $38.5(6.4)$ & $41.8(10.0)$ \\
\hline Employment (y, mean (SD)) & $11.7(7.9)$ & $13.7(8.2)$ \\
\hline \multicolumn{3}{|l|}{ Workers admitted to hospital: } \\
\hline Men (n) & 142 & 336 \\
\hline Women $(n)$ & & 99 \\
\hline Age $(y$, mean (SD)) & $33.5(5.6)$ & $35.6(10.1)$ \\
\hline Employment (y, mean (SD)) & $9.0(7.0)$ & $10.3(8.2)$ \\
\hline \multicolumn{3}{|c|}{ Workers admitted to hospital for cardiovascular diseases: } \\
\hline $\operatorname{Men}(n)$ & 5 & 27 \\
\hline Women (n) & 0 & 1 \\
\hline Age $l y$, mean $(S$ & $37.3(7.0)$ & $37.6(10.4)$ \\
\hline Employment (y, mean (SD)) & $13.6(10.3)$ & $11.9(9.6)$ \\
\hline
\end{tabular}

protein (an IgA receptor) by immunohistochemistry with an antibody against secretor component and in situ hybridisation according to our previously published method. ${ }^{17}$

\section{Data analyses}

Descriptive analysis of the demographic data and work history of all workers and the workers who had been admitted to hospital was performed. The morbidity odds ratios (ORs) of various diseases due to the exposure in a news printing factory was calculated as in a case-control study, ${ }^{18}$ with the case being various diseases that resulted in admission to hospital of the worker. There were two control groups in this study. The first control group was workers admitted to hospital for cardiovascular diseases. We lumped all workers who were admitted to hospital due to diseases other than the diseases of interest and cardiovascular diseases as another control group. Multiple logistic regression analysis was used to estimate morbidity OR adjusted for age, duration of employment, sex, and other possible risk factors. The statistical package SAS/STAT PC 6.08 was used for data analyses. ${ }^{19}$

\section{RESULTS}

There were 1564 workers identified as having worked in the factory since its establishment in 1950. Of these workers there were 1326 men and 238 women; 336 of them had worked in the printing factory; 1228 workers worked in non-printing sectors. The mean (SD) age of the workers was 41.1 (9.4) years and the mean (SD) duration of employment in the company was 13.3 (8.2) years. Workers of printing factories were younger with shorter duration of employment than nonprinting workers. The difference was not significant (table 1). A significantly higher proportion of men worked in printing than non-printing departments.

Of the 1564 people who had worked in this company, the total admissions to hospital was 796 during the observation period. After discounting repeated admission to hospitals with the same diagnosis, there were 579 workers who were admitted to hospital at least once. We first chose cardiovascular diseases as the reference. Morbidity ORs for nasopharyngeal carcinoma, benign skin tumours, chronic pharyngitis or sinusitis, chronic liver disease or cirrhosis, and mechanical injuries were significantly related to printing works. Five out of 144 printing workers admitted to hospital were diagnosed with nasopharyngeal carcinoma compared with none of the other 435 non-printing workers admitted to hospital. Because one of the $2 \times 2$ cells was zero, we added $1 / 2$ to calculate the crude morbidity OR of nasopharyngeal carcinoma, ${ }^{20}$ which was 57.0 (95\% confidence interval (95\% CI) 2.8 to 1155.3 , Fisher's exact test, $\mathrm{p}<0.001$ ).

When workers admitted to hospital due to diseases other than the disease of interest and cardiovascular disease as control group, all diseases of interest showed a significant trend except chronic liver disease or cirrhosis of the liver, as shown in table 2 .

The mean (SD, range) duration of employment of the patients with nasopharyngeal carcinoma in this printing factory was $13.5(7.2,4.5-20.2)$ years. The mean age of these patients at the time of pathologic proof of nasopharyngeal carcinoma was $44.7(14.5,35.5-70.5)$ years, table 3.

The initial symptoms included bloody rhinorrhea, neck mass, nasal obstruction, hearing impairment, blurred vision, ptosis, and diplopia. Three out of five patients received the serological test for antibodies against EBV. Only one patient had a normal antibody titre of the viral capsid antigen associated with the EBV (EBVCA) in IgA class. The other two patients showed EBVCA IgA 1:20 and 1:160 respectively. Two patients died in 1993 and the other patients did not show any evidence of recurrence after radiotherapy and chemotherapy (table 3). 
Table 2 Adjusted MORs for those diseases that showed significant relations with printing works*

\begin{tabular}{|c|c|c|c|c|c|c|}
\hline Diseases & Printing workers & $\begin{array}{l}\text { Non-printing } \\
\text { workers }\end{array}$ & MOR+ & $95 \% \mathrm{Cl} \dagger$ & MOR $\ddagger$ & $95 \% \mathrm{Cl}$ \\
\hline Nasopharyngeal carcinoma§ & 5 & 0 & 57.0 & 2.8 to 1155.3 & 33.8 & 1.9 to 613.8 \\
\hline Benign skin tumours & 5 & 1 & 28.0 & 2.7 to 293.1 & 15.3 & 1.8 to 132.3 \\
\hline Chronic pharyngitis or sinusitis & 4 & 1 & 29.4 & 1.7 to 514.7 & 6.9 & 1.2 to 39.2 \\
\hline Mechanical injuries & 6 & 2 & 21.9 & 2.6 to 187.2 & 7.6 & 1.9 to 30.0 \\
\hline Chronic liver disease or liver cirrhosis & 5 & 6 & 6.0 & 1.1 to 31.8 & 3.1 & 0.88 to 11.1 \\
\hline Lower respiratory tract infection & 1 & 15 & 1.0 & & & \\
\hline Skin and subcutaneous disease & 5 & 8 & 6.4 & & & \\
\hline Musculoskeletal disorder & 6 & 17 & 1.9 & & & \\
\hline Cardiovascular diseases & 5 & 28 & 1.0 & & & \\
\hline
\end{tabular}

*Adjusted for age, sex, and working duration; †Cardiovascular disease as the reference disease; $¥ D$ iseases other than diseases of interest as the reference disease; §Crude morbidity odds ratio (MOR) with exact estimates for $95 \% \mathrm{Cl}$.

Table 3 Characteristics and clinical findings of workers affected with nasopharyngeal carcinoma

\begin{tabular}{|c|c|c|c|c|c|}
\hline & \multicolumn{5}{|l|}{ Patient No } \\
\hline & 1 & 2 & 3 & 4 & 5 \\
\hline Age at diagnosis & 35.5 & 38.0 & 70.5 & 39.2 & 40.3 \\
\hline Year of diagnosis & 1986 & 1987 & 1987 & 1990 & 1993 \\
\hline Working years & 14.5 & 14.3 & 20.2 & 13.0 & 15.3 \\
\hline Initial symptoms & $\begin{array}{l}\text { Hearing impairment, } \\
\text { nasal obstruction }\end{array}$ & Neck mass, diplopia & Blurred vision, ptosis & Neck mass, bloody rhinorrhoea & Bloody rhinorrhoea \\
\hline $\begin{array}{l}\text { Histological } \\
\text { finding }\end{array}$ & $\begin{array}{l}\text { Undifferentiated } \\
\text { carcinoma }\end{array}$ & $\begin{array}{l}\text { Poorly differentiated } \\
\text { carcinoma }\end{array}$ & Undifferetiated carcinoma & $\begin{array}{l}\text { Undifferetiated carcinoma with } \\
\text { feature of } \\
\text { lympho-epitheliomatous } \\
\text { carcinoma }\end{array}$ & Undifferetiated carcinoma \\
\hline Clinical staging & T4NOMO & T4N1M1 & T4NOMO & $\mathrm{T} 2 \mathrm{~N} 2 \mathrm{MO}$ & T1N2MO \\
\hline \multicolumn{6}{|c|}{ Epstein-Barr viruscapsid antigen: } \\
\hline $\begin{array}{l}\lg A \\
\lg G\end{array}$ & N/A & $\begin{array}{l}1: 160 \\
1: 640\end{array}$ & N/A & $\begin{array}{l}1: 20 \\
1: 160\end{array}$ & $\begin{array}{l}<1: 10 \\
1: 160\end{array}$ \\
\hline Current status & $\begin{array}{l}\text { No evidence of } \\
\text { recurrence }\end{array}$ & $\begin{array}{l}\text { Died in } 1993 \text { (brain } \\
\text { metastasis) }\end{array}$ & Died in 1993 (stroke) & No evidence of recurrence & $\begin{array}{l}\text { No evidence of } \\
\text { recurrence }\end{array}$ \\
\hline
\end{tabular}

Four cases of nasopharyngeal carcinoma biopsy specimens showed a picture of undifferentiated nasopharyngeal carcinoma, and one of them seemed to have a lymphoepitheliomatous carcinoma. In situ hybridisation of EBER-1 in the four cases showed some tumour cells without EBV signal. The EBV signal was found in a few tumour cells in two of them (cases 1 and 4) and was seen in more tumour cells in the other two (cases 3 and 5); in these some infiltrating lymphocytes also showed an EBV signal.

When double localisation of EBV and secretor component protein was performed, some tumour cells showed neither EBV signal nor secretor component protein; a few tumour cells showed both EBV signal and secretor component immunostaining; other tumour cells either showed secretor component only or EBV signal with a very weak secretor component, a picture identical with our previously published data. ${ }^{17}$

\section{DISCUSSION}

The aetiology of nasopharyngeal carcinoma is probably multifactorial. ${ }^{8}$ 11-14 $21^{11}$ Although we have found an increased morbidity OR of nasopharyngeal carcinoma in printing workers, it does not necessarily follow that nasopharyngeal carcinoma was caused by printing works. Evidence and arguments strongly suggest such a possibility. Firstly, eating salty fish ${ }^{12-14}$ and taking herbal drugs, ${ }^{21}$ were reported to be risk factors for nasopharyngeal carcinoma. But none of our patients had such habits. Secondly, smoking was reported to be associated with a twofold to threefold increased risk of nasopharyngeal carcinoma. ${ }^{12}$ Yu et al found that smoking for more than 30 pack-years gave a twofold increase of nasopharyngeal carcinoma among ethnic Chinese. ${ }^{11}$ Although all five patients in our series were smokers, they usually smoked less than 1 pack/day because the company policy prohibited smoking at the workplace for fear of explosion and fire. As four out of five patients were below 41 years of age at the time of diagnosis, they were unlikely to have accumulated more than 30 pack-years. Thus, smoking alone seemed inadequate to explain the increased risk of nasopharyngeal carcinoma among printing workers. Thirdly, as the income levels, which were major determinants for smoking and dietary habits, ${ }^{22}{ }^{23}$ seemed similar (800 US\$/month for printers $v 650$ for non-printing workers). The likelihood of a major difference in these lifestyle habits may be low. Because both printing workers and non-printing workers had been working in an air conditioned system, the factor of merely poor ventilation cannot explain the difference of occurrence. Rather, workplace exposure must have contributed a significant portion, given that workers were under a closed air condition system to conserve energy. We conclude that all the suspected risk factors for nasopharyngeal carcinoma are not likely to be confounding factors in this study.

In the Chinese population, the incidence of nasopharyngeal carcinoma is unusually high. The annual incidence of nasopharyngeal carcinoma in Taiwan was 4.2/100 000. ${ }^{9}$ In these 1564 workers with a mean duration of 13.3 working years, the total working years were around 20800 . The expected number of cases of nasopharyngeal carcinoma in the whole newspaper company should be 0.8 during this period. We identified five cases of nasopharyngeal carcinoma and all were printing workers. If the observed five cases were divided by the expected 0.15 cases of nasopharyngeal carcinoma in printing workers, the morbidity ratio was 32 . The result was 
very consistent despite selection of two different control groups, either cardiovascular disease or all diseases other than diseases of interest, as shown in table 2.

As infection with EBV has been proposed to be closely associated with the development on nasopharyngeal carcinoma, ${ }^{142627}$ and one of our patients has a high titre of IgA antibody against EBVCA $(1: 160)$, there is a possibility that nasopharyngeal carcinoma in this patient may have been induced by EBV infection. However, although a positive EBV signal was found in some tumour cells in each case, we found that all four specimens of nasopharyngeal carcinoma contained tumour cells free from EBV. This finding indicates that EBV infection is not the only causative factor for the development of nasopharyngeal carcinoma in these four cases, as we found previously. ${ }^{16}{ }^{17}$ Furthermore, the presence of EBV and secretor component positive cells in the sections indicates that EBV may infect the secretor component positive nasopharyngeal carcinoma tumour cells, instead of secretor component negative tumour cells, through the endocytosis of EBV-IgAsecretor component complex as we previously described, and possibly that EBV was not a causative factor in the induction of nasopharyngeal carcinoma in these patients.

Cancers of the lung, urinary bladder, and liver were once reported to be associated with printing works. ${ }^{1-7}$ It is not surprising that such carcinogens might have a similar effect on the nasopharynx, especially in ethnic Chinese, of whom the structure of the nasopharynx is generally narrower and more easily deposited with aerosols compared with the nasopharynx of white people. Printing workers have been exposed to a panoply of potentially toxic substances, including pigments, inks, solvents, resins, driers, plasticisers and wetting agents, ${ }^{7}$ which might have a direct irritative effect and produce chronic pharyngitis or sinusitis. Printing ink mixed with mineral oil might contain procarcinogens-such as benzoxy-a-pyrenes. Some printing pigments contain toxic heavy metals-such as chromium and lead. The environmental monitoring in the factory identified the presence of toxic solvents-such as tetrachloroethane, benzene, toluene, styrene, and $n$-hexane. We conducted an exposure assessment of chemicals in the printing workplace and detected trace concentration of formaldehyde $\left(1.4-31.1 \mu \mathrm{g} / \mathrm{m}^{3}\right)$, sulfuric acid $\left(0.03-0.13 \mathrm{mg} / \mathrm{m}^{3}\right)$, and aerosol of mineral oils $\left(0.02-0.13 \mathrm{mg} / \mathrm{m}^{3}\right)$ after there had been some improvement in cleaning and ventilation of the workplace. $^{25}$ Although they were below the permissible concentrations, long term effects might still be hazardous, especially under a combined exposure to other potential carcinogens and in a closed system of indoor air conditioning. These toxic substances may coexist as aerosol and precipitate in the nasopharyngeal mucosa, causing repeated or chronic inflammation or even malignant change after a certain induction time.

More than $90 \%$ of nasopharyngeal carcinomas in Taiwan are undifferentiated, non-keratinising carcinoma diagnosed at a mean age around $45 .^{28}{ }^{29}$ It was unusual to see that printing workers with undifferentiated, non-keratinising carcinoma had a mean age of 39.1 (table 3). One possible explanation was early carcinogenesis due to exposure of toxic substances. Among the workers with nasopharyngeal carcinoma, four had worked in the printing factory for more than 13 years before the date of diagnosis. One worker only spent 4.5 working years in the factory before the onset of nasopharyngeal carcinoma. However, this worker admitted that he had worked in another printing factory for 10 years before taking the current job. Thus the induction period of nasopharyngeal carcinoma would be more than 10 years.

Cardiovascular diseases were used as the reference diseases because cardiovascular diseases were not reported to be associated with printing works. We even used diseases other than the disease of interest as a second reference group. The result did not differ much. Except for chronic liver disease or cirrhosis of the liver, all diseases in table 2 remain significantly asso- ciated with printing works. The reason why OR decreased might be due to the effect of including some diseases that may also be related to printing. As we only had complete data from one newspaper company, the case number was relatively small and the estimated $95 \%$ CI of the morbidity OR was wide.

Both skin and the liver are vulnerable to toxic chemicals in printing factories because they are either the defence organ against toxic substance or the organ of detoxification. Primary liver cancer, cirrhosis of the liver, and skin cancer were reported to be increased in printing workers. ${ }^{67}$ Organic solvents used in the printing factory might cause liver injury and the long term exposure to these solvents might contribute to the development of cirrhosis of the liver. In Taiwan, hepatitis $B$ virus (HBV) caused most cases of cirrhosis of the liver and primary liver cancer. ${ }^{30}$ As the prevalence of HBV carriers in printing and non-printing workers was similar $(14.1 \%$ and $13.0 \%$, respectively), the increased risk of cirrhosis of the liver was probably related to work. We thought that a longer duration of follow up or increased numbers in the study populations in the future might show a clearer tendency. Further study should identify whether these diseases progress to the development of nasopharyngeal carcinoma. Occupational injury remained a problem of concern in printing factories and most injuries were reported to occur during the process of cleaning or repair of machines.

Results from this study of a cohort containing a group of workers from a newspaper printing company support the conclusion that printing works are associated with an increased risk of nasopharyngeal carcinoma, chronic pharyngitis or sinusitis, cirrhosis of the liver, and mechanical injuries. Health surveillance, hazard control, and a programme of injury prevention should be implemented in all newspaper printing factories.

\section{ACKNOWLEDGEMENTS}

We are indebted to Professor Mow-Ming Hsu and Sister Mary Ellen Kerrigan for thorough review and helpful comments on the manuscript of the paper. The project is supported partially by a grant from the National Science Council of the Republic of China No NSC89-2314-B-002-433-M56.

\section{Authors' affiliations}

Y-H Liu, C-L Du, C-C Chan, J-D Wang, Institute of Occupationa Medicine and Industrial Hygiene, National Taiwan University College of Public Health; and Department of Internal Medicine, National Taiwan University Hospital Taipei, No 1, Section 1, Jen-Ai Road, Taipei, Taiwan 10016

Y-H Liu, Department of Family Medicine, National Taiwan University Hospital and Cardinal Tien Hospital, Taipei, Taiwan

C-L Du, Institute of Occupational Safety and Health, Council of Labor Affairs, Executive Yuan, Taipei, Taiwan

C-T Lin, Department of Pathology, National Taiwan University Hospital, Taipei, Taiwan

C-J Chen, Graduate Institute of Epidemiology, National Taiwan

University College of Public Health, Taipei, Taiwan

\section{REFERENCES}

1 Lynge E, Rix BA, Villadsen E, et al. Cancer in printing workers in Denmark. Occup Environ Med 1995;52:728-44.

2 Moss E, Scott TS, Atherley GRC. Mortality of newspaper workers from lung cancer and bronchitis 1952-66. Br J Ind Med 1972;29:1-14.

3 Greenberg $M$. A proportional mortality study of a group of newspaper workers. Br J Ind Med 1972;29:15-20.

4 Leon DA. Mortality in the British printing industry: a historical cohort study of trade union members in Manchester. Occup Environm Med 1994;51:79-86.

5 Lloyd JW, Decoufle P, Salvin LG. Unusual mortality experience of printing pressmen. J Occup Med 1997; 19:543-50.

6 Paganini-Hill A, Glazer E, Henderson BE, et al. Cause-specific mortality among newspaper web pressman. J Occup Med 1980;22:542-4.

7 Greene $\mathbf{M H}$, Hoover RN, Eck RL, et al. Cancer mortality among printing plant workers. Environ Res 1979;20:66-73.

8 Hildesheim A, Levine PH. Etiology of nasopharyngeal carcinoma: a review. Epidemiol Rev 1993;15:466-85. 
9 Wang YF, Tsai SF, Hsu KH, et al. Epidemiologic characteristics of malignant neoplasms in Taiwan: V. nasopharyngeal carcinoma. Journal of the National Public Health Association of the Republic of China 1989:9:46-57.

10 Shanmugaratnam K. Nasopharynx. In: Schottenfeld D, Fraumeni JF Jr, eds. Cancer epidemiology and prevention. Philadelphia: WB Saunders, 1982:536-53

11 Yu MC, Garabrant DH, Huang TB, et al. Occupational and other non-dietary risk factors for nasopharyngeal carcinoma in Guangzhou, China. Int J Cancer 1990;45:1033-9.

12 Lin TM, Chen KP, Lin CC, et al. Retrospective study on nasopharyngeal carcinoma. J Natl Cancer Inst 1973;51:1403-8.

13 Lin TM, Chang HJ, Chen CJ, et al. Risk factors for nasopharyngeal carcinoma. Anticancer Res 1986:6:791-6.

14 Chen CJ, Liang KY, Chang YS, et al. Multiple risk factors of nasopharyngeal carcinoma: Epstein-Barr virus, malarial infection, cigarette smoking and familial tendency. Anticancer Res 1990; 10:547-54.

15 Slater LC, Arnott SE, Jacobsen N, et al. Using Foxpro 2.5 for windows. Carmel: Que, 1993:187-344

16 Lin CT, Dee AN, Chen W, et al. Association of Epstein-Barr virus, human papilloma virus and human cytomegalovirus in nine nasopharyngeal carcinoma cell lines. Lab Invest 1994;71:731-6.

17 Lin CT, Lin CR, Tan GK, et al. The mechanism of Epstein-Barr virus infection in nasopharyngeal carcinoma cells. Am J Pathol 1997:150:1745-56

18 Miettinen OS, Wang JD. An alternative to the proportionate mortality ratio. Am J Epidemiol 1981;114-118.

19 SAS Institute. SAS/STAT user's guide, release 6.03 edition. Cray, NC: SAS Institute, 1988
20 Kahn HA, Sempos CT. Statistical methods in epidemiology. Oxford. UK: Oxford University Press, 1989:57.

21 Chen CJ, Wang YF, Shieh TI, et al. Multifactorial etiology of nasopharyngeal carcinoma, Epstein-Barr virus, familial tendency and environmental cofactors. Head and neck oncology research. Proceedings of the 2nd International Head and Neck Oncology Research Conference. 1987;469-476.

22 Sterling TD, Weinkam JJ. Smoking characteristics by the type of employment. J Occup Med 1976;18:743-54.

23 Covey LS, Wynder EL. Smoking habits and occupation status. J Occup Med 1981;23:537-42.

24 Ho CK, Lo WCH, Huang PH, et al. Suspected nasopharygeal carcinoma in three workers with long-term exposure to sulfuric acid vapor. Occup Environ Med 1999;56:426-8.

25 Tsai HJ. Exposure assessment of chemical hazards on newspaper printing workers [master thesis]. Taipei: National Taiwan University of Public Health 1997:61-75.

26 Henle W, Henle G, Ho HC. Antibodies to Epstein-Barr virus in nasopharyngeal carcinoma, other head and neck neoplasms, and control groups. J Natl Cancer Inst 1970;44:225-30.

27 Chen JY, Chen CJ, Liu MY, et al. Antibodies to Epstein-Barr virus-specific DNAase in patients with nasopharyngeal carcinoma and control groups. J Med Virol 1987;23:11-21.

28 Hsu MM, Tu SM. Nasopharyngeal carcinoma in Taiwan: clinical manifestations and results of therapy. Cancer 1983:52:362-8.

29 Hsu MM, Lin BL. Characterisation of T cell subsets using monoclonal antibodies in nasopharyngeal carcinoma patients. Ann Otol Rhinol Laryngol 1986;95:298-301.

30 Lin TM, Tsu WT, Chen CJ. Mortality of hepatoma and cirrhosis of liver in Taiwan. Br J Cancer 1986;54:969-76.

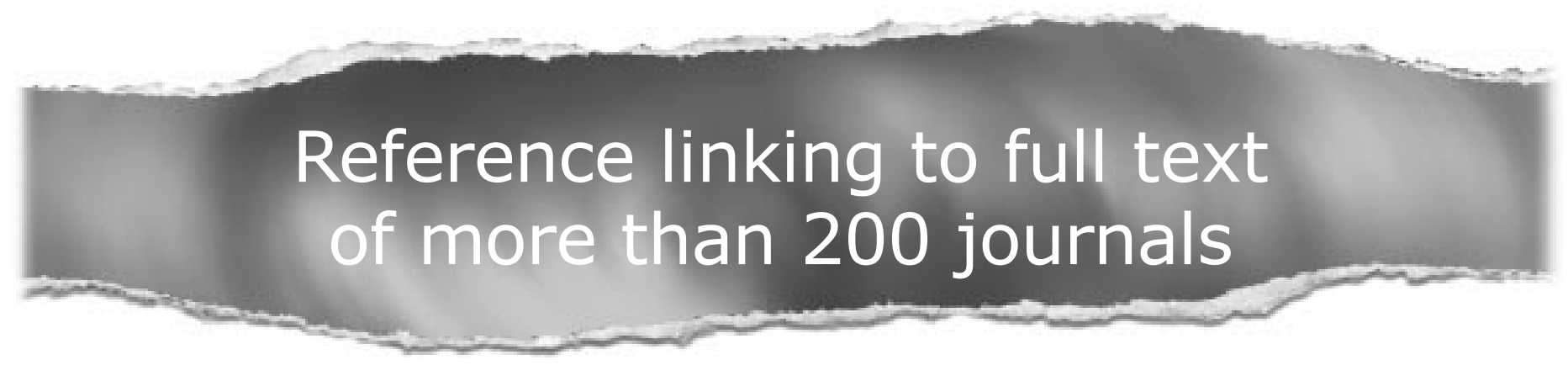

\section{Toll free links}

You can access the FULL TEXT of articles cited in Occupational and Environmental Medicine online if the citation is to one of the more than 200 journals hosted by HighWire (http://highwire.stanford.edu) without a subscription to that journal.

There are also direct links from references to the Medline abstract for other titles.

www.occenvmed.com 